\section{Faculty support and student engagement in undergraduate engineering}

Department of Electrical and Computer Engineering, University of Washington Seattle Campus, Seattle, Washington, USA

Lauren Summers

Department of Teaching, Learning, and Curriculum, University of Washington Seattle Campus, Seattle, Washington, USA, and Joanna Wright Department of Learning Sciences and Human Development, University of Washington Seattle Campus, Seattle, Washington, USA

\begin{abstract}
Purpose - This study investigated how behavioral and emotional forms of engagement are associated with faculty support and student-faculty interactions among engineering students.

Design/methodology/approach - Quantitative research methods were used to analyze survey data from 781 undergraduates in seven large undergraduate engineering courses. Linear hierarchical regression models were used to evaluate the relationships between demographics (gender, race/ethnicity, family education, US status and transfer status) and student engagement and between faculty behaviors and engagement.

Findings - Faculty support was consistently, significantly and positively linked to all forms of student engagement, while student-faculty interactions were significantly and positively linked to effort and positive emotional engagement and negatively linked to attention and (an absence of) negative emotional engagement. Gender, race/ethnicity, international student status and transfer status significantly predicted at least one form of engagement.

Research limitations/implications - Although this was a single institution study and cross-sectional, the findings suggest that faculty support and student-faculty interactions, while important for engagement, have different effects on different types of students. Faculty and teacher professional development efforts should raise awareness of these differences in order to enhance diversity and inclusion in engineering courses and curricula at all levels.

Originality/value - The analysis of behavioral and emotional forms of engagement represents more of a motivational lens on engagement in contrast to the traditional focus on time-on-task or time spent in fruitful educational practices, as is the norm with much of the engagement literature in higher education.
\end{abstract}

Keywords Faculty support, STEM, Engineering, Engagement, Emotion, Motivation

Paper type Research paper

(C) Denise M. Wilson, Lauren Summers and Joanna Wright. Published in Journal of Research in Innovative Teaching \& Learning. Published by Emerald Publishing Limited. This article is published under the Creative Commons Attribution (CC BY 4.0) licence. Anyone may reproduce, distribute, translate and create derivative works of this article (for both commercial and non-commercial purposes), subject to full attribution to the original publication and authors. The full terms of this licence may be seen at http://creativecommons.org/licences/by/4.0/legalcode

The author would like to gratefully acknowledge the National Science Foundation for their support of this work (DUE grant number 1504618). Any opinions, findings, and conclusions or recommendations expressed in this material are those of the author(s) and do not necessarily reflect the views of the National Science Foundation. The author would also like to thank the statistical consulting resources provided by the Center for Statistics and the Social Sciences, University of Washington. support and
student
engagement

83

Faculty

Received 16 February 2020 Revised 15 March 2020 Accepted 17 March 2020 


\section{JRIT \\ 13,1}

\section{The importance of faculty}

Faculty can influence student experiences in college both through formal class support and interactions that contribute to students' academic integration in college and through informal interactions such as those associated with extracurricular activities which influence students' social integration in college. In turn, both academic and social integration are key contributors to students' ability and decision to complete a degree (Tinto, 1993).

Faculty Support of Students: The teaching practices that faculty use and other efforts faculty make to support students have often predicted students' academic performance and engagement. For example, Umbach and Wawrzynski (2005) demonstrated in a large multiinstitutional study that student engagement is higher at institutions where faculty used active and collaborative learning techniques and challenged students academically. Faculty support including expressions of care and respect has also been associated with positive feelings toward and emotional commitment to an institution (LaMastro, 2001) as well as improved academic performance (Torregosa et al., 2016), and for male STEM students, improved mathematical self-concept (Kim and Sax, 2018). In other studies, faculty support did not directly predict outcomes such as student satisfaction, but mediated the relationship between student effort and student satisfaction (Fredrickson, 2012).

In engineering, student satisfaction with faculty availability and the quality of instruction and advice was found to be negatively correlated with students being disengaged across a broad range of engineering majors at four different institutions (Chen et al., 2008). And, over time, general perceptions of faculty support across multiple courses predicted behavioral and emotional engagement at smaller, teaching-oriented institutions but not at large research institutions (Wilson et al., 2014). While this research reinforces the importance of faculty support in the student experience, relatively little is known about how different demographic populations, particularly under-represented groups, may perceive and respond differently to such support.

Faculty Interactions with Students: Faculty and peers are largely regarded as the two primary agents of socialization on a college campus, and despite the powerful influence of peer groups on student values, attitudes and development, informal interactions with faculty can be sufficiently powerful to exceed the influence of the general student culture (Lamport, 1993). More specifically, in a study of over 4,500 students at various doctoral and master's level institutions, Lundberg and Schreiner (2004) found that the quality of facultystudent relationships significantly predicted learning for all ethnic groups. In a more recent study of 242 students at a single mid-size institution, students who thought that faculty were available to interact with them outside the classroom, reported higher academic self-concept and intrinsic motivation in their studies than those who thought faculty were less accessible (Komarraju et al., 2010). Course-related student-faculty interactions have also been significantly linked to GPA for Asian-American students (Cole, 2010). And, in an effort to study 43,000 students from 119 majors across nine campuses, student-faculty interactions were consistently and significantly associated with greater levels of cognitive development (Kim and Sax, 2011). However, a recent study brought into question the importance of student-faculty interactions by demonstrating that for millennial students, student-faculty interactions significantly predicted neither student satisfaction in the first year nor retention in the second year of the undergraduate program (Romsa et al., 2017). This study contradicted earlier studies which demonstrated that student-faculty interactions had significant positive impacts on student satisfaction (Kuh and $\mathrm{Hu}, 2001$ ) and on retention (Lamport, 1993).

In an effort to further understand whether millennial students are different from their predecessors in terms of the impact faculty have on their educational experience, this study examined how student-faculty interactions were related to multiple forms of student 
engagement. Consistent with recommendations from Gellin that emerged from a metaanalysis of student involvement which includes interactions with faculty (Gellin, 2003), this study also narrowed the context of studying student-faculty interactions to specific courses rather than more generalized contexts which extend across multiple courses or other campus activities.

\section{Measuring student engagement}

Student engagement is most frequently measured in terms of what students do (rather than what they think and feel) and is measured broadly across multiple courses or academic and non-academic activities. The most comprehensive and far-reaching survey on engagement among college students in the US is the National Survey of Student Engagement (NSSE) which was introduced in 1999 to gather information about the quality of colleges and universities and, in its present form, is completed annually by students at over 531 colleges and universities (National Survey of Student Engagement, n.d.). Of particular interest to academic courses on the NSSE are student-faculty interactions (e.g. how often have you talked about career plans with a faculty member?) and effective teaching practices (e.g. to what extent have your instructors taught course sessions in an organized way?) ((National Survey of Student Engagement, 2019). These measures are similar to measures of faculty support and faculty interactions used in this study.

Other items on the NSSE that relate to academic courses seek to understand how much time students spend in higher order learning (e.g. how much has your coursework involved evaluating a point of view, decision or information source?), reflective and integrative learning (e.g. how often have you connected your learning to societal problems or issues?), learning strategies (e.g. how often have you identified key information from reading assignments?) and quantitative reasoning (e.g. how often have you reached conclusions based on your own analysis of numerical information?) (NSSE Engagement Indicators, n.d.). Rather than focusing on time spent in these specific activities or other tasks, this study looked at underlying motivators of what students choose to do with their time. Behavioral engagement includes both observable measures such as asking questions and participating in class discussions and non-observable motivators like attention and effort (Fredricks et al., 2004). This study examined the less observable measures of attention and effort. Behavioral engagement is particularly important because it has been shown to influence other forms of engagement (e.g. emotional), link what teachers do with student achievement and mediate behaviors that are critical to learning (Fredericks, 2013).

In addition to behavioral engagement measures of attention and effort, emotional engagement measures seek to capture the emotional motivators behind other forms of engagement. Positive emotions are key elements to human adaption and learning, and while high-intensity emotions may impair attention, focus and motivation, low-intensity positive emotions are likely to do the opposite by increasing the ability to regulate behavior (Valiente et al., 2012). For example, enjoyment is a low-intensity emotion that has been linked to better academic performance (Pekrun et al., 2006; Ferris and Gerber, 1996; Puca and Schmalt, 1999). Low-intensity positive emotions can also promote better cognitive and academic functioning by broadening cognition and awareness of potential solutions to difficult problems (Cohn and Fredrickson, 2009). The emotion of interest is likely to help students pay attention and, in so doing, perform better (Valiente et al., 2012). Interest and curiosity are also likely to result in higher achievement by increasing motivation to seek out additional learning resources (Valiente et al., 2012) and enhancing intrinsic motivation and locus of control (Pekrun, 2006).

In contrast, negative emotional engagement can signal a lack of or a barrier to motivated behavior. For example, worry and anxiety diminish the capacity and capability of working memory, which, in turn, detrimentally impacts academic performance. Situational anxiety
Faculty
support and
student
engagement 
JRIT

13,1

86

has been linked to negative academic outcomes including diminished test performance and grades (Duchesne et al., 2008; Seipp, 1991). Anxiety and worry can also disrupt memory and the ability to recall material (Linnenbrink, 2007; Linnenbrink et al., 1999; Rice et al., 2007). Anxiety among students can lead to poor performance because these negative emotions decrease motivation or incite withdrawal (Davidson et al., 2000), which, in turn, reduces other forms of engagement (Linnenbrink, 2007).

Like behavioral engagement measures, studies which focus on the emotional aspects of engagement in college are not commonplace despite their demonstrated importance in individual success. To contribute to this gap in the understanding of engagement among college students, this study measured both positive and negative emotional engagement as well as effort and attention.

\section{Research questions}

This study investigated connections between faculty support, faculty interactions and student engagement, resulting in the following research questions:

$R Q 1$. Are faculty support or faculty interactions significantly related to student engagement?

Previous studies of how faculty behavior relates to student engagement have been largely limited to engagement associated with time-on-task and time spent in high-value educational activities. This study focused instead on the more internal states of engagement related to attention and effort as well as positive and negative emotional engagement. Insight into these relationships may also extend outside of the college classroom into other engineering learning settings in K-12, continuing education for adults or informal learning environments in engineering and STEM.

$R Q 2$. Do different types of students appear to respond to faculty differently?

Prior research has shown that faculty support can influence different groups of students differently. This study expanded on this notion by evaluating which demographic variables and faculty behaviors interact in relation to both behavioral and emotional engagement. Insight gained from this research question can be applied to expanding diversity and inclusion in engineering and other STEM courses.

\section{Methods}

This study was based on a survey that was specifically designed to measure faculty support, faculty-student interactions and student engagement. The study was conducted at a single large public university classified as a doctoral university with very high research activity (Carnegie Foundation, 2018). Class enrollment in the courses surveyed ranged from 60 to 250 students.

\section{Participants}

Students from seven different sophomore-level engineering courses (four in electrical and computer engineering, three in mechanical engineering) were recruited between fall 2016 and spring 2018 to complete a survey about the course in which they were enrolled. A total of 781 students completed the survey, representing $85 \%$ of students enrolled overall in the seven courses and between $30 \%$ and $91 \%$ of students in each course, with no duplications (i.e. no student was enrolled in more than one of the courses studied). In addition to standard background variables of race and gender, the survey included additional demographic questions related to socioeconomic status, including family income, mother's education, 
father's education and socioeconomic class. Due to small sample sizes, minority racial groups were consolidated into two groups: Black ( $N=27,3.5 \%$ of the sample) and other (non-Black) under-represented minorities (URM) which made up $8.6 \%$ of the sample $(N=67)$. The latter group included Pacific Islander, American Indian, Alaska Native and other racial groups that were not Asian, Black or White. Most students were male $(N=585,74.9 \%)$ and either Asian $(N=357,45.7 \%)$ or Caucasian $(N=311,39.8 \%)$. Most were US citizens or permanent residents $(N=633 ; 81.0 \%)$, and were not transfer students $(N=568,72.7 \%)$. And, most students came from middle-income $(N=315,40.3 \%)$ families earning annual incomes between $\$ 20,000$ and $\$ 80,000$, or from high-income families $(N=259,33.2 \%)$ earning more than $\$ 80,000$ a year. Most students also came from families where the mother had earned an associate's or bachelor's degree $(N=391,50.1 \%)$ or a graduate degree $(N=185,23.7 \%)$.

\section{Measures}

The dependent variables used in this analysis (Table 1) were based on two behavioral forms of engagement (attention and effort) and two emotional forms of engagement (positive and negative) using items that were adapted for use in higher education (Wilson et al., 2015) from previous studies in $K-12$ (Miserandino, 1996).

All engagement items were assessed using a 5-point Likert scale ranging from 1 (strongly disagree) to 5 (strongly agree). Although negative emotional engagement had an internal reliability that was less than the standard 0.7 , there is evidence that reliability between 0.6 and 0.7 is adequate (George and Mallery, 2014). All four engagement variables were processed and coded such that higher scores meant better engagement. Thus, higher negative emotional engagement scores effectively represented the absence of worry, anxiety and discouragement as reported by students.

The independent variables used to represent faculty behaviors in this study were adapted from previous measures of academic support, teaching practices and faculty contact. Four items were used from engagement indicators related to teaching practices in the NSSE (National Survey of Student Engagement, 2019), five items were adapted from the teacher academic support subscale developed by Van Ryzin et al. (2009) and six additional items were adapted from the faculty contact scale used by Einarson and Clarkberg (2010). Exploratory factor analyses (EFA) were conducted independently on the faculty behavior items using varimax rotation to identify useable scales for this study. The number of factors was initially determined by an eigenvalue threshold of 1 while also considering the point at which the scree plot for the eigenvalues leveled off, and adding additional factors explained little additional variance in the data. Items that demonstrated communalities of less than 0.5 and failed to demonstrate a strong $(>0.6)$ loading on any single factor were discarded. Items that loaded onto more than one factor $(>0.4)$ were also discarded. After items were discarded, any remaining factors which contained at least two items were retained for analysis. The results of this EFA produced two measures: faculty support and faculty interactions (with students). Sample items from each scale are provided in Table 2.

\section{Data analysis}

The data were analyzed using SPSS 19 to compute descriptive statistics, perform EFA of the faculty behavior items, evaluate skewness and kurtosis of the engagement variables,

\begin{tabular}{ll}
\hline Primary Scale & Sample Item \\
\hline Behavioral attention $(\alpha=0.83)$ & When I'm in this class, my mind wanders \\
Behavioral effort $(\alpha=0.78)$ & I try hard to do well in this class \\
Positive emotional engagement $-\operatorname{PEE~}(\alpha=0.75)$ & I enjoy learning new things in this class \\
Negative emotional engagement $-\operatorname{NEE~}(\alpha=0.67)$ & In this class, I feel discouraged
\end{tabular}

\section{Faculty support and student engagement}


JRIT
13,1

compute the reliability of the faculty and engagement scales, evaluate the suitability of independent and dependent variables for analysis and construct the hierarchical regression models for analysis.

Demographics were chosen for inclusion in the regression models for this analysis based on insight gained from the existing literature. Gender was included in the model because women remain highly under-represented in engineering education at $19.8 \%$ of all bachelor's degrees (National Science Foundation, 2019) and face multiple barriers, biases and negative stereotypes in engineering programs (Blackburn, 2017). Racial and ethnic minorities also struggle in engineering due to limited access to a high-quality education, discrimination and lack of encouragement (Pew Resaerch Center, 2018).

Those students who are the first in their family to attend college are also underrepresented in engineering. While $56 \%$ of undergraduates were first-generation college students in 2015-2016, students who are not first-generation can outnumber first-generation students in engineering by as much as 2:1 ratio (Eismann, 2016). First-generation students often come from different socioeconomic and family income levels than their peers, and the identities, interests, performance, family support and self-efficacy of these students are often different than students who come from families with college experience, thus altering the internal landscape and comfort levels of these students in engineering classrooms (Verdin and Godwin, 2015). International students suffer from a lack of familiarity with US education systems, and despite over one million international students attending college in the USA (Institute of International Education, 2019), international students face barriers ranging from cultural intolerance to inhospitality and unfairness. (Lee and Rice, 2007). And finally, the struggles that transfer students from community colleges face, particularly in STEM disciplines, are so prevalent that they have a familiar label to describe them - transfer shock (Cejda, 1997).

These demographics were effect coded into the regression models for engagement as follows:

(1) Gender (male $=-1$; female $=1$ ).

(2) Black (White or Asian $=-1$; Black = 1; other URM =0).

(3) Other URM (White or Asian $=-1$; Black $=0$; other URM $=1$ ).

(4) Low income (family income between $\$ 20,000 /$ year and $\$ 80,000 /$ year $=-1$; less than $\$ 20,000 / \mathrm{yr}=1$; more than $\$ 80,000 / \mathrm{yr}=0$ ).

(5) High income (family income between $\$ 20,000 /$ year and $\$ 80,000 /$ year $=-1$; less than $\$ 20,000 / \mathrm{yr}=0$; more than $\$ 80,000 / \mathrm{yr}=1)$.

(6) No degree (mother's education includes $\mathrm{AA}, \mathrm{AS}, \mathrm{BS}$ or $\mathrm{BA}$ degree $=-1$; a graduate degree like an $\mathrm{MS}, \mathrm{PhD}$ or $\mathrm{JD}=0$; no degree $=1$ ).

Table 2.

Faculty support and faculty interaction variables

\section{Sample Items}

\begin{tabular}{ll}
\hline Primary Scale & Sample Items \\
\hline $\begin{array}{l}\text { Faculty support } \\
(\alpha=0.90)\end{array}$ & $\begin{array}{l}\text { The professor in this class is willing to spend time outside of class to discuss } \\
\text { issues that are of interest and importance to me }\end{array}$ \\
& $\begin{array}{l}\text { The professor in this class is interested in helping me learn } \\
\text { The professor in this class is available when I need help }\end{array}$ \\
$\begin{array}{l}\text { Faculty interactions } \\
(\alpha=0.92)\end{array}$ & $\begin{array}{l}\text { I have discussed career plans with the professor in this class } \\
\text { I have discussed academic work with the professor in this class }\end{array}$ \\
& I have attended office hours to see the professor in this class
\end{tabular}


(7) Grad degree (mother's education includes AA, AS, BS or BA degree $=-1$; a graduate degree like an $\mathrm{MS}, \mathrm{PhD}$ or $\mathrm{JD}=1$; no degree $=0$ ).

(8) US status (US citizen or permanent resident $=-1$; international student $=1$ ).

(9) Transfer status (native or non-transfer $=-1$; transfer $=1$ ).

Faculty
support and
student
engagement

89

Demographics and faculty support and faculty interactions variables were integrated into four hierarchical linear regression models, each representing a different form of engagement. Initially, each model considered all possible interactions between demographic variables and faculty variables, one interaction at a time. If an interaction reduced the Bayesian (BIC) criterion and the Akaike information criterion (AIC) for the model, that interaction and its complementary interaction (with faculty support or faculty interactions) were retained in the model. If interactions between a demographic variable and both faculty support and faculty interactions resulted in an increase in the AIC and BIC, the interactions were discarded from the model. The resulting parsimonious models for each form of engagement were retained for analysis.

Finally, a mixed model using HLM (hierarchical linear modeling) was constructed to understand whether nesting of students within courses affected the engagement variables. The results of a null HLM model (i.e. one that did not contain the independent variables) confirmed that the variance contributed to all four forms of engagement at the course level was not significant. Thus, the results of hierarchical regression were unlikely to be confounded by these nesting effects, and linear regression emerged as an appropriate means to analyze these data.

\section{Results}

Skewness and kurtosis of the engagement variables were first calculated to confirm variable normality. Skewness of all four engagement variables was between 0 and -0.5 , indicating that the variables were approximately symmetric. Kurtosis for all variables ranged between 0 and -1 , indicating that the distributions of the engagement variables were neither too flat nor too peaked. Thus, the engagement variables were assumed to be sufficiently normally distributed to proceed with analysis (George and Mallery, 2010). Bivariate correlations between pairs of engagement variables were all below 0.5 . Therefore, all four engagement variables were retained.

\section{Descriptive statistics}

Descriptive statistics for faculty support, faculty interactions, the two forms of behavioral engagement (attention, effort) and the two forms of emotional engagement (positive PEE, negative NEE) are summarized in Table 3 . All variables were scaled to values between 1 and 5 to facilitate comparisons between measures.

\section{Behavioral engagement models}

Two, three-level regression models were constructed for behavioral engagement (Table 4).

In both models, the independent demographic variables used in the first level of each model explained little of the variance in the data (3\% for attention and $2.3 \%$ for effort). Including faculty support and faculty interactions substantially strengthened each of the

\begin{tabular}{lccccccr}
\hline & Faculty Support & Faculty Interactions & PEE & NEE & Attention & Effort & \\
\cline { 1 - 4 }$N$ & 692 & 700 & 704 & 715 & 711 & 715 & \\
Mean & 3.94 & 1.66 & 3.46 & 3.14 & 2.77 & 3.87 & Table 3. \\
Standard deviation & 0.64 & 0.89 & 0.77 & 0.95 & 0.98 & 0.79 & Descriptive statistics \\
\hline
\end{tabular}


JRIT 13,1

90 models so that demographics and faculty variables together explained $6 \%$ and $17 \%$ of the variance in the data for attention and effort, respectively.

\section{Attention (Table 5)}

The model for attention was the weakest of the two models for behavioral engagement. Thus, the results for the attention models should be interpreted with caution, as any statistically significant results may have only small practical significance. The results in Table 5 indicate that being an international student consistently and positively predicted

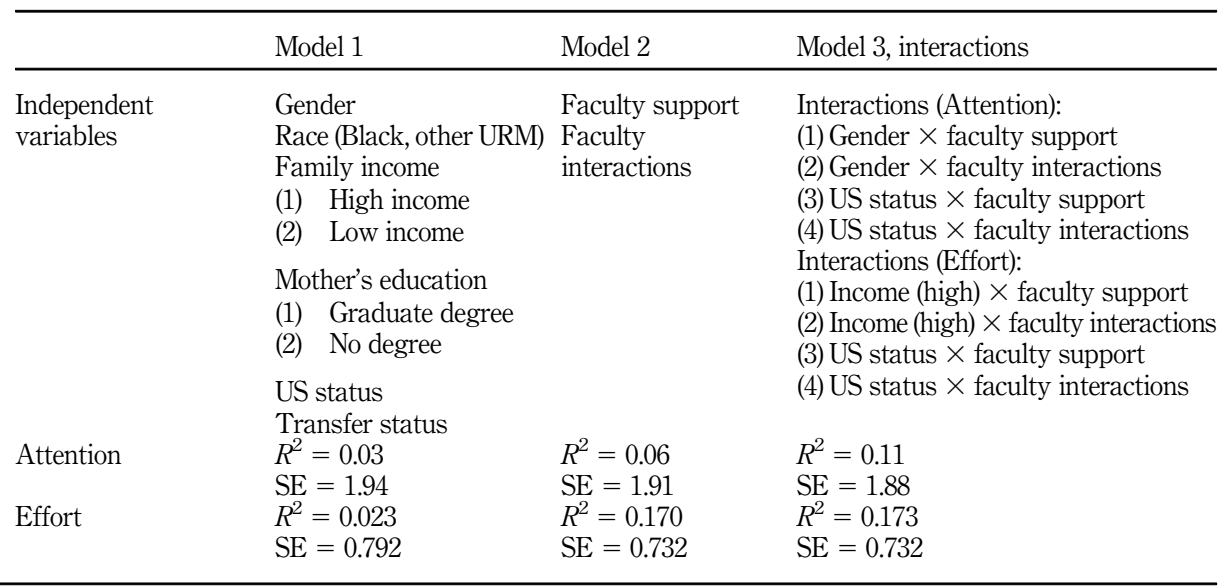

Table 4.

Summary of linear regression models for behavioral engagement

\begin{tabular}{|c|c|c|c|c|c|c|}
\hline \multirow[b]{2}{*}{ Predictor variable } & \multicolumn{2}{|c|}{ Model 1} & \multicolumn{2}{|c|}{ Model 2} & \multicolumn{2}{|c|}{ Model 3} \\
\hline & $B(\mathrm{SE})$ & $p$ & $B(\mathrm{SE})$ & $p$ & $B(\mathrm{SE})$ & $p$ \\
\hline Constant & $2.94(0.16)$ & $0.00^{* * *}$ & $2.15(0.29)$ & $0.00^{* * * *}$ & $2.47(0.38)$ & $0.00 * * *$ \\
\hline Gender & $-0.02(0.05)$ & 0.71 & $-0.03(0.05)$ & 0.57 & $-0.00(0.05)$ & 0.95 \\
\hline Race (Black) & $0.01(0.17)$ & 0.95 & $0.01(0.17)$ & 0.97 & $-0.04(0.16)$ & 0.83 \\
\hline Race (other URM) & $-0.00(0.12)$ & 0.99 & $0.00(0.12)$ & 0.96 & $0.01(0.12)$ & 0.91 \\
\hline \multicolumn{7}{|l|}{ Income } \\
\hline High & $-0.05(0.07)$ & 0.45 & $-0.05(0.07)$ & 0.45 & $-0.06(0.07)$ & 0.35 \\
\hline Low & $-0.02(0.11)$ & 0.88 & $0.00(0.11)$ & 0.99 & $0.02(0.11)$ & 0.83 \\
\hline \multicolumn{7}{|l|}{ Mother's education } \\
\hline No degree & $-0.02(0.10)$ & 0.85 & $-0.03(0.10)$ & 0.77 & $-0.05(0.10)$ & 0.58 \\
\hline Graduate degree & $0.01(0.21)$ & 0.95 & $0.05(0.20)$ & 0.81 & $0.09(0.20)$ & 0.67 \\
\hline US status & $0.14(0.06)$ & $0.02 *$ & $0.15(0.06)$ & $0.01 *$ & $0.17(0.06)$ & $0.00 * *$ \\
\hline Transfer status & $0.11(0.05)$ & $0.02 *$ & $0.12(0.05)$ & $0.01^{*}$ & $0.10(0.05)$ & $0.04^{*}$ \\
\hline Faculty support & & & $0.49(0.13)$ & $0.00 * * *$ & $0.19(0.09)$ & $0.04 *$ \\
\hline Faculty interactions & & & $-0.18(0.09)$ & 0.06 & $-0.12(0.07)$ & 0.08 \\
\hline \multicolumn{7}{|l|}{ Gender X } \\
\hline Faculty support & & & & & $0.10(0.05)$ & $0.04 *$ \\
\hline Faculty interactions & & & & & $0.05(0.06)$ & $0.37 *$ \\
\hline \multicolumn{7}{|l|}{ US status $X$} \\
\hline Faculty support & & & & & $-0.15(0.05)$ & $0.00 * *$ \\
\hline Faculty interactions & & & & & $-0.15(0.05)$ & $0.00 * *$ \\
\hline \multicolumn{7}{|c|}{ Note(s): $* p<0.05 ; * * p<0.01 ; * * * p<0.001$} \\
\hline
\end{tabular}

Table 5.

Hierarchical regression models for attention

Faculty interactions
Note(s): $* p<0.05 ; * *<<0.01 ; * * * p<0.001$ 
attention. The unstandardized regression coefficients for US status changed little from model 1 ( $B=0.14)$ to model $2(B=0.15)$, which suggests that faculty support and faculty interactions variables had little, if any, mediating or confounding effect on how and why international students paid more attention. A similar result emerged for transfer students. Transfer students paid more attention in their courses than native (non-transfer) students both when faculty support and faculty interaction variables were taken into account (model 2) and when only demographics were included (model 1). The unstandardized regression coefficient for transfer status also remained relatively consistent from model $1(B=0.11)$ to model $2(B=0.12)$.

In the second-level model, faculty support significantly and positively predicted attention $(B=0.49, p=0.00)$ although because of small effect sizes $\left(R^{2}=0.06\right.$ at level 2$)$, the practical significance of this relationship may be limited. While the significance of the relationship between faculty interactions and attention $(\phi=0.06)$ was not within conventional significance limits $(\phi<0.05)$, the fact that the unstandardized coefficient was negative $(B=-0.18)$ merited further investigation. To gain further insight into the role of faculty interactions in student attention, an additional regression model was generated and excluded those students who reported "never" interacting with faculty. Among the remaining students $(N=481)$, faculty contact was a negative and significant predictor of attention $(B=-0.16, \mathrm{SE}=0.06 ; p=0.00)$. This result strongly suggested that for those students who do interact with faculty, the more faculty interactions they had, the less they paid attention in class. Finally, when considering interactions in the third level of the model for attention, interactions between gender and faculty support and US status and both faculty support and faculty interactions were significant. While the relationship between faculty support and attention was significant and positive for both males and females (Figure 1), the relationship was more pronounced for women, suggesting that at high levels of faculty support, females may benefit more in terms of paying attention.

In contrast, the relationships between faculty support and faculty interactions and attention were significant and negative for international students but positive for domestic students (Figure 2).

Also noteworthy is that the relationship between faculty interactions and support for domestic students was flat, suggesting that these interactions made little difference in the attention paid by domestic students.

\section{Effort (Table 6)}

Among the demographic variables considered in the first level of the model (model 1), being Black significantly and positively predicted effort $(p=0.04 ; B=0.28 ; \mathrm{SE}=0.13$ ) as did being

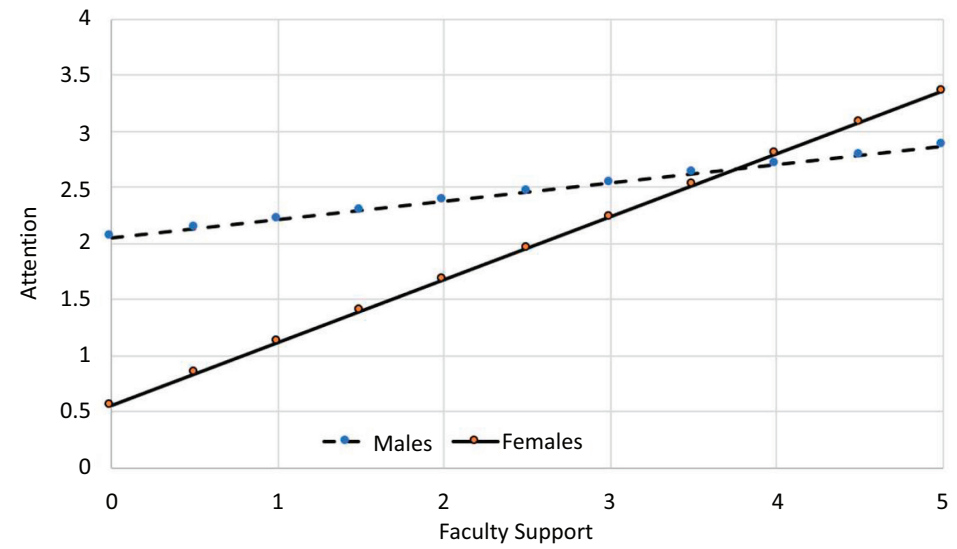

Faculty support and student engagement
Figure 1.

Interactions between gender and faculty support 


\section{JRIT 13,1}

\section{2}

Figure 2.

Interactions between US status and faculty support and interactions

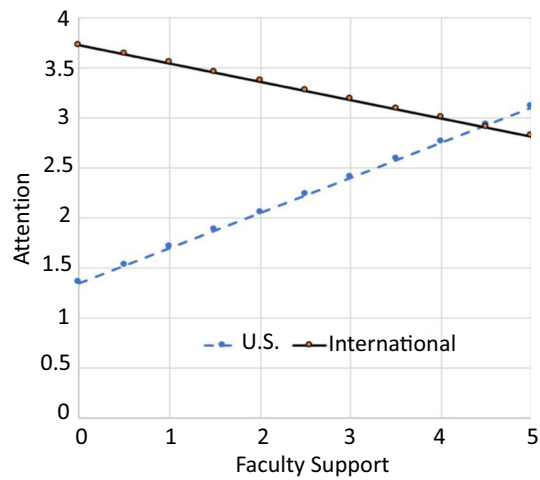

(a)

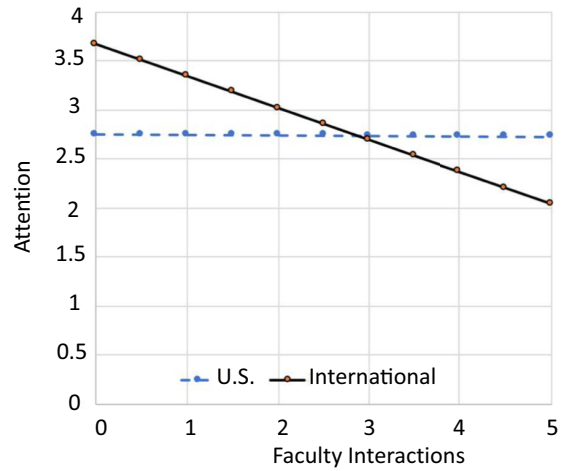

(b)

\begin{tabular}{|c|c|c|c|c|c|c|}
\hline \multirow[b]{2}{*}{ Predictor variable } & \multicolumn{2}{|c|}{ Model 1} & \multicolumn{2}{|c|}{ Model 2} & \multicolumn{2}{|c|}{ Model 3} \\
\hline & $B$ (SE) & $P$ & $B$ (SE) & $p$ & $B(\mathrm{SE})$ & $p$ \\
\hline Constant & $3.95(0.13)$ & $0.00 * * *$ & $2.14(0.22)$ & $0.00 * * *$ & $1.95(0.26)$ & $0.00 * * *$ \\
\hline Gender & $0.01(0.04)$ & 0.77 & $0.02(0.04)$ & 0.54 & $0.02(0.04)$ & 0.54 \\
\hline Race (Black) & $0.28(0.13)$ & $0.04 *$ & $0.18(0.12)$ & 0.16 & $0.19(0.12)$ & 0.12 \\
\hline Race (other URM) & $-0.19(0.10)$ & 0.06 & $-0.14(0.09)$ & 0.14 & $-0.16(0.09)$ & 0.09 \\
\hline \multicolumn{7}{|l|}{ Income } \\
\hline High & $-0.04(0.06)$ & 0.54 & $-0.04(0.05)$ & 0.48 & $-0.04(0.05)$ & 0.47 \\
\hline Low & $0.10(0.09)$ & 0.25 & $0.11(0.08)$ & 0.17 & $0.11(0.08)$ & 0.19 \\
\hline \multicolumn{7}{|l|}{ Mother's education } \\
\hline No degree & $0.03(0.08)$ & 0.73 & $0.00(0.07)$ & 0.98 & $0.01(0.08)$ & 0.87 \\
\hline Graduate degree & $-0.10(0.17)$ & 0.54 & $-0.00(0.16)$ & 0.98 & $-0.02(0.16)$ & 0.89 \\
\hline US status & $0.01(0.05)$ & 0.83 & $-0.02(0.04)$ & 0.69 & $-0.01(0.04)$ & 0.81 \\
\hline Transfer status & $0.08(0.04)$ & $0.05 *$ & $0.05(0.04)$ & 0.13 & $0.05(0.04)$ & 0.13 \\
\hline Faculty support & & & $0.41(0.05)$ & $0.00 * * *$ & $0.46(0.06)$ & $0.00 * * *$ \\
\hline Faculty interactions & & & $0.13(0.04)$ & $0.00 * * *$ & $0.11(0.04)$ & $0.01^{*}$ \\
\hline \multicolumn{7}{|l|}{ Income (high) $X$} \\
\hline Faculty support & & & & & $0.06(0.03)$ & 0.07 \\
\hline Faculty interactions & & & & & $0.01(0.04)$ & 0.82 \\
\hline \multicolumn{7}{|l|}{ US status $X$} \\
\hline Faculty support & & & & & $0.07(0.04)$ & 0.08 \\
\hline Faculty interactions & & & & & $-0.03(0.04)$ & 0.48 \\
\hline \multicolumn{7}{|c|}{$\operatorname{Note}(\mathbf{s}): * p<0.05 ; * * p<0.01 ; * * * p<0.001$} \\
\hline
\end{tabular}

Table 6.

Hierarchical regression models for effort a transfer student $(\phi=0.05 ; B=0.08 ; \mathrm{SE}=0.04) . R^{2}$ for model 1 , however, was small, and these effects were not significant in model 2 when faculty support and faculty interactions were added to the model. However, follow-up analysis of variance (ANOVA) indicated that Black students put forth significantly more effort than both White and Asian students $(p=0.02)$ and other URM students $(p=0.02)$. Independent samples $t$-tests also indicated that transfer students put forth significantly more effort than native (non-transfer) students.

In the second level (model 2) for effort, both faculty support and faculty interactions significantly and positively predicted effort $(p<0.001)$, although faculty support appeared to be a stronger predictor $(B=0.41)$ than faculty interactions $(B=0.13)$. The third-level model 
considered only two pairs of interactions involving high income and US status. None of these interactions were significant.

\section{Emotional engagement models}

Two, three-level hierarchical models were also constructed for positive and negative emotional engagement. As with the behavioral engagement models, the independent variables used in the first level of each model explained little of the variance in the data (only $4.3 \%$ and $1.6 \%$ for the positive and negative emotional engagement models, respectively). Including the two faculty variables in the second level of the model, however, produced a much stronger model for both emotional engagement measures, allowing $31 \%$ and $13 \%$ of the variance in the data to be explained by the model (Table 7).

\section{Positive emotional engagement (Table 8)}

Being an international student consistently, positively and significantly predicted positive emotional engagement. While the practical significance of this relationship may be limited by the small effect size in the first-level model $\left(R^{2}=0.043\right)$, its importance is underscored by the fact that the relationship remained significant in the second model where effect size was larger. Also in the second model, both faculty support and faculty interactions predicted positive emotional engagement, although faculty support $(\phi=0.00 ; B=0.52 ; \mathrm{SE}=0.04)$ was a stronger predictor than faculty interactions $(\phi=0.00 ; B=0.16$; $\mathrm{SE}=0.03)$.

Transfer students were likely to be experiencing faculty interactions differently as indicated by the significant interaction between transfer status and faculty interactions. A closer look at this interaction (Figure 3) suggests that the emotions of transfer students are less sensitive to faculty interactions than those reported by native (non-transfer) students.

\section{Negative emotional engagement (Table 9)}

While positive emotional engagement reflects how much students enjoy and are interested in their courses, negative emotional engagement reflects the absence of negative emotions such as discouragement and anxiety. The regression model for negative emotional engagement was not as strong as for positive emotional engagement, but it nevertheless produced some interesting results. Both being female and being a member of an under-represented racial/

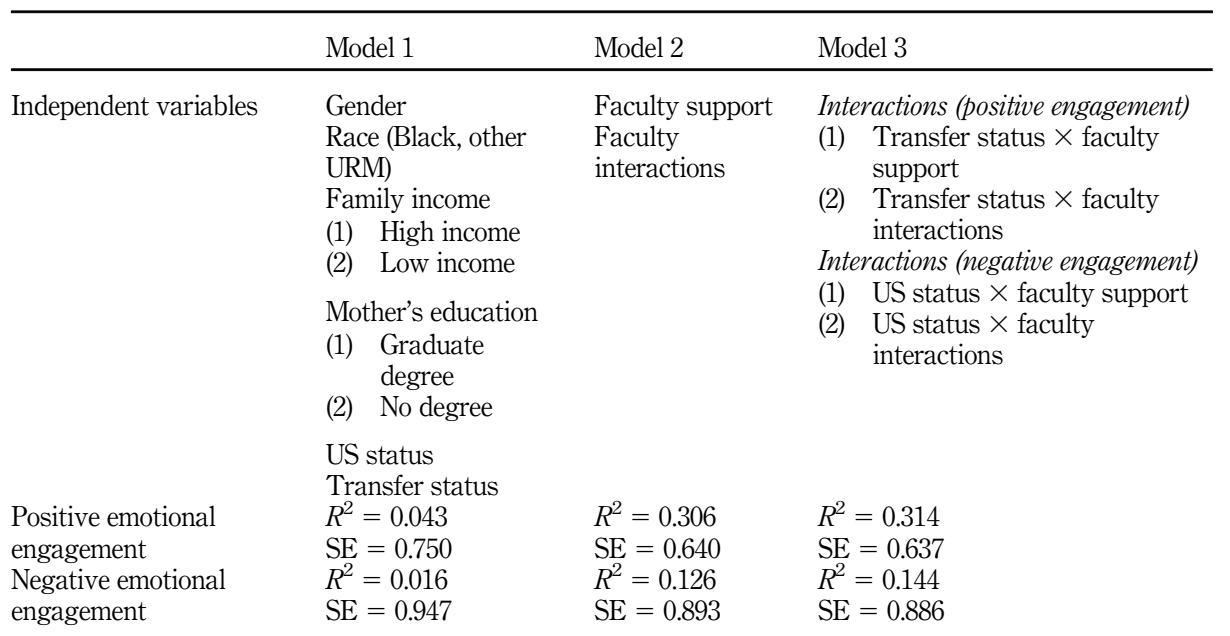

Faculty support and student engagement

93




\section{JRIT 13,1}

94

\begin{tabular}{|c|c|c|c|c|c|c|}
\hline \multirow[b]{2}{*}{ Predictor variable } & \multicolumn{2}{|c|}{ Model 1} & \multicolumn{2}{|c|}{ Model 2} & \multicolumn{2}{|c|}{ Model 3} \\
\hline & $B$ (SE) & $p$ & $B(\mathrm{SE})$ & $p$ & $B(\mathrm{SE})$ & $p$ \\
\hline Constant & $3.57(0.12)$ & $0.00 * * * *$ & $1.28(0.19)$ & 0.00 & $1.37(0.21)$ & $0.00^{* * *}$ \\
\hline Gender & $-0.06(0.04)$ & 0.10 & $-0.04(0.03)$ & 0.17 & $-0.04(0.03)$ & 0.17 \\
\hline Race (Black) & $0.20(0.13)$ & 0.12 & $0.07(0.11)$ & 0.54 & $0.06(0.11)$ & 0.55 \\
\hline Race (other URM) & $-0.10(0.09)$ & 0.30 & $-0.03(0.08)$ & 0.71 & $-0.03(0.08)$ & 0.69 \\
\hline \multicolumn{7}{|l|}{ Income } \\
\hline High & $-0.05(0.06)$ & 0.38 & $-0.05(0.05)$ & 0.27 & $-0.06(0.05)$ & 0.20 \\
\hline Low & $0.06(0.09)$ & 0.49 & $0.08(0.07)$ & 0.28 & $0.11(0.07)$ & 0.15 \\
\hline \multicolumn{7}{|l|}{ Mother's education } \\
\hline No degree & $0.14(0.08)$ & 0.07 & $0.10(0.07)$ & 0.12 & $0.10(0.07)$ & 0.11 \\
\hline Graduate degree & $-0.17(0.16)$ & 0.31 & $-0.04(0.14)$ & 0.78 & $-0.05(0.14)$ & 0.75 \\
\hline US status & $0.12(0.04)$ & $0.01 *$ & $0.09(0.04)$ & $0.02 *$ & $0.08(0.04)$ & $0.03^{*}$ \\
\hline Transfer status & $0.07(0.04)$ & 0.08 & $0.04(0.03)$ & 0.23 & $0.04(0.03)$ & 0.18 \\
\hline Faculty support & & & $0.52(0.04)$ & $0.00 * * *$ & $0.51(0.05)$ & $0.00 * * *$ \\
\hline Faculty interactions & & & $0.16(0.03)$ & $0.00 * * *$ & $0.14(0.03)$ & $0.00 * * *$ \\
\hline \multicolumn{7}{|l|}{ Transfer status $X$} \\
\hline Faculty support & & & & & $-0.01(0.03)$ & 0.65 \\
\hline Faculty interactions & & & & & $-0.07(0.03)$ & $0.01 *$ \\
\hline \multicolumn{7}{|c|}{$\operatorname{Note}(\mathbf{s}): * p<0.05 ; * * p<0.01 ; * * * p<0.001$} \\
\hline
\end{tabular}

Figure 3.

Interactions between transfer status and faculty interactions

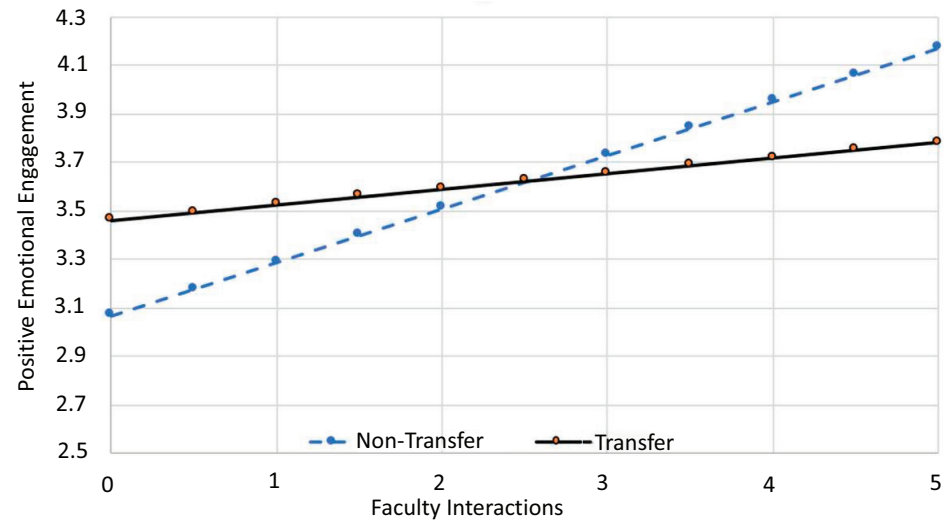

ethnic minority that was not Black (i.e. other URM) negatively and significantly predicted negative emotional engagement. This result implies that women and other URM students feel more anxiety in their courses than males and members of other racial groups. Consistent with the other engagement models in this study, both faculty support and faculty interactions significantly predicted negative emotional engagement, but faculty interactions did so negatively. This result means that students who reported stronger faculty support reported fewer feelings of anxiety and discouragement, but students who reported more faculty interactions reported more of these feelings.

Interactions between US status and faculty support were also significant in the model for negative emotional engagement. A closer look at these interactions is shown in Figure 4. International students appeared to be predisposed to more negative feelings in the 


\begin{tabular}{|c|c|c|c|c|c|c|c|}
\hline \multirow[b]{2}{*}{ Predictor variable } & \multicolumn{2}{|c|}{ Model 1} & \multicolumn{2}{|c|}{ Model 2} & \multicolumn{2}{|c|}{ Model 3} & \multirow{2}{*}{$\begin{array}{r}\text { Faculty } \\
\text { support and }\end{array}$} \\
\hline & $B$ (SE) & $p$ & $B$ (SE) & $p$ & $B$ (SE) & $p$ & \\
\hline Constant & $3.18(0.16)$ & $0.00 * * *$ & $2.49(0.27)$ & $0.00 * * *$ & $2.99(0.32)$ & $0.00^{* * * *}$ & \\
\hline Gender & $-0.09(0.05)$ & 0.06 & $-0.12(0.04)$ & $0.01 *$ & $-0.11(0.04)$ & $0.01 *$ & enga \\
\hline Race (Black) & $0.19(0.16)$ & 0.23 & $0.26(0.15)$ & 0.09 & $0.24(0.15)$ & 0.12 & \\
\hline Race (other URM) & $-0.20(0.12)$ & 0.09 & $-0.24(0.11)$ & $0.03^{*}$ & $-0.23(0.11)$ & $0.04^{*}$ & \\
\hline \multicolumn{8}{|l|}{ Income } \\
\hline High & $0.11(0.07)$ & 0.10 & $0.12(0.07)$ & 0.07 & $0.12(0.07)$ & 0.07 & \\
\hline Low & $-0.02(0.11)$ & 0.13 & $-0.12(0.10)$ & 0.22 & $-0.12(0.10)$ & 0.22 & \\
\hline \multicolumn{8}{|l|}{ Mother's education } \\
\hline No degree & $-0.09(0.10)$ & 0.33 & $-0.11(0.09)$ & 0.23 & $-0.13(0.09)$ & 0.16 & \\
\hline Graduate degree & $0.19(0.20)$ & 0.36 & $-0.22(0.19)$ & 0.25 & $0.25(0.19)$ & 0.19 & \\
\hline US status & $-0.02(0.06)$ & 0.72 & $0.04(0.05)$ & 0.47 & $0.06(0.05)$ & 0.30 & \\
\hline Transfer status & $0.03(0.05)$ & 0.49 & $0.06(0.04)$ & 0.17 & $0.05(0.04)$ & 0.23 & \\
\hline Faculty support & & & $0.34(0.06)$ & $0.00 * * *$ & $0.24(0.08)$ & $0.00^{* * * *}$ & \\
\hline Faculty interactions & & & $-0.33(0.04)$ & $0.00 * * *$ & $-0.38(0.05)$ & $0.00^{* * * *}$ & \\
\hline \multirow{3}{*}{\multicolumn{5}{|c|}{$\begin{array}{l}\text { US status } X \\
\text { Faculty support } \\
\text { Faculty interactions }\end{array}$}} & & & \\
\hline & & & & & $-0.11(0.05)$ & 0.03 & Hierarchical regression \\
\hline & & & & & $-0.09(0.05)$ & $0.07^{*}$ & \\
\hline \multicolumn{5}{|c|}{ Note(s): $* p<0.05 ; * * p<0.01 ; * * * p<0.001$} & & & emotional enga \\
\hline
\end{tabular}

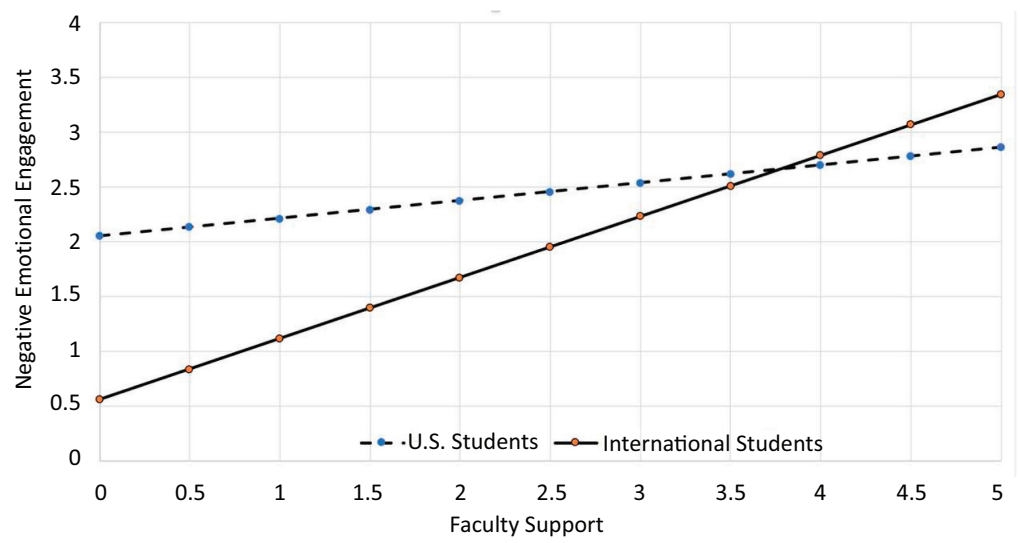

Figure 4.

Interactions between US status and faculty support

classroom, but also appeared to be more responsive to faculty support than their domestic (US) peers.

\section{Discussion}

RQ1. Are faculty support or faculty interactions significantly related to student engagement?

In all four engagement models, faculty support positively predicted engagement and did so more strongly than was the case for faculty interactions. This suggests that the availability, preparation, respect and care that faculty project to students have a positive impact on both behavioral and emotional student engagement, although a longitudinal study would be required to prove causality. Faculty support was associated with stronger positive feelings in the classroom (as is reflected in positive emotional engagement) and fewer negative feelings (as is reflected in higher negative emotional engagement scores) in this study, a result which is 
JRIT

13,1

96

consistent with a 2001 study (LaMastro, 2001) that showed a positive connection between faculty support and positive feelings and emotional commitment to the student's home institution. When students perceived that faculty care and are interested in their learning (i.e. faculty support is high), they also performed better academically (Torregosa et al., 2016). The stronger connections between faculty support and engagement compared to faculty interactions and engagement may be a direct result of the fact that all students experienced faculty support to some level, but many fewer students actually had the opportunity to interact with faculty, particularly in large classes.

Nevertheless, the regression models also indicated the importance of faculty interactions with students. Faculty interactions positively and significantly predicted both effort and positive emotional engagement but negatively predicted negative emotional engagement (i.e. an absence of negative feelings in the classroom). A negative association between faculty interactions and attention may also be emerging from our data $(\phi=0.06)$. Thus, faculty interactions appear to be associated with different effects on different types of engagement. While students who interact with faculty reported putting forth more effort and feeling better about their courses, they may also have experienced increased negative emotions when having frequent interactions with faculty. This may seem counterintuitive, but if stressed out and anxious students are seeking out faculty, they may have experienced a resulting increase in their positive emotions (e.g. interest and enjoyment) about a course as a result. A more intuitive result from these data is that students who have more interactions with faculty put forth more effort which stands to reason as students must seek faculty out to interact with them.

Overall, the results of this study add to previous research regarding the significance of faculty interactions with and faculty support of students by providing insight into how students' emotional and behavioral engagement may be impacted by what faculty do.

\section{RQ2: Do different types of students appear to respond to faculty differently?}

Gender: In the models associated with this study, female students appeared to be predisposed to more feelings of worry and discouragement (i.e. lower negative emotional engagement scores) than men (Table 9). This is not surprising considering that women spoke of isolation (Brainard and Carlin, 1998) and a lack of belonging and fit (Marra et al., 2007) when considering leaving engineering for other majors. Further, feelings of inclusion tended to decline rather than improve over time for women in engineering (Marra et al., 2009). In turn, sense of belonging, fit and inclusion has been negatively correlated to feelings of loneliness, anxiety and depression among college students (Hagerty et al., 1996).

In addition, in our models, women also appeared to respond more strongly to faculty support than men (Figure 1). Given the reduced sense of belonging that women in engineering may experience, strong faculty support may provide the necessary elements to succeed in specific courses, and also provide a sense of care and respect for female students which serve to strengthen feelings of belonging and inclusion and, in turn, reduce negative feelings about coursework. Previous research has highlighted this possibility by demonstrating that courserelated faculty interactions and faculty mentoring predicted an increased sense of belonging, as did discussions with peers about academic and career issues (Johnson, 2012).

Race/Ethnicity: When faculty support and interactions were taken into account, being a member of an under-represented racial/ethnic minority negatively predicted negative emotional engagement. This means that other (non-Black) URM students reported fewer positive feelings about their courses for a given level of faculty support or faculty interactions than their Black, White and Asian peers. The lack of interaction effects between race/ethnicity and faculty support or faculty interactions suggests that these students do not respond differently to increased levels of faculty support or interactions, a result that seems inconsistent 
with previous literature which showed that interacting with faculty facilitated greater academic achievement for certain URM students (Anaya and Cole, 2001) and that minority students of color reported greater engagement as measured by NSSE indicators (Ancar, 2008). Noteworthy is the fact that the Ancar's (2008) study combined both Asian and Black students with other URM students into a single minority population, while this study evaluated Black and other URM students separately (Asian students were not under-represented minorities in this study). The results suggest a need for further studying URM populations as separate groups, as their engagement experiences in engineering can be quite distinct.

US Status: International students tend to enter US universities and colleges experiencing greater stress and concern about their studies than domestic students due to bureaucratic requirements, isolation, lack of proficiency and comfort with speaking English (Poyrazli and Grahame, 2007), as well as psychological feelings of homesickness, powerlessness and disorientation (Smith and Khawaja, 2011). Combined, these stressors can lead to feelings of anxiety (Ebbin, 1988) that are reflected in the depressed negative emotional engagement (i.e. greater feelings of worry and discouragement) scores that international students reported in this study at low and moderate levels of faculty support (Figure 4). However, faculty support and faculty interactions have been found to surpass peer support in developing feelings of belonging and inclusion among international students (Glass et al., 2015), so much so that "simple, even otherwise unremarkable acts of care and concern" are interpreted as significant acts of inclusion (Glass et al., 2015, p. 363). The strong boost in negative emotional engagement scores that occurred with increasing faculty support in our data (Figure 4) reflects this influential role that faculty have on facilitating inclusiveness among international students.

Surprisingly in our study, increasing faculty support was not consistently associated with increased engagement. Negative and significant associations emerged between faculty support and interactions and attention (Figure 2). International students paid less attention with increasing faculty support and faculty interactions. A possible explanation for this is that some international students are paying less attention in class because of language or other cultural barriers, and so they are seeking out faculty to compensate for this lack of attention; the resulting increase in faculty interactions is providing those students with a greater sense of faculty care, respect and support.

Transfer Students: Being a transfer student positively and significantly predicted behavioral engagement (measured as attention and effort), a result which contradicts previous studies which demonstrated that transfer students are less engaged than native students (Ishitani and McKitrick, 2010). This is likely a direct result of the different measures of engagement used in the two studies. Attention and effort (used in this study) are primarily motivational measures, while the Ishitani and McKitrick's (2010) study used participation in academic and collaborative learning as a form of engagement. In the Ishitani and McKitrick's (2010) study, native students reported greater time spent in academic and collaborative learning (as a form of engagement) compared to transfer students, while native students paid less attention and put forth less effort in this study. The striking difference in results may reflect that although transfer students are more motivated to succeed once they enter into their four-year institution, culture shock and adjustment difficulties may prevent them from fully participating in educationally engaging activities.

\section{Limitations}

This study was limited to seven engineering courses at a single institution. Thus, we cannot claim that our findings are generalizable to other engineering courses at other institutions. Furthermore, sample sizes of both Black and other URM students were small, which may have reduced the possibility of finding significant results within the data. Despite small sample sizes, this study demonstrated that students' response to faculty support and faculty interactions is likely different, depending on gender, race/ethnicity, US status and transfer

\section{Faculty support and student engagement}


JRIT

13,1

status. Another important limitation of this study is that the collected data are cross-sectional in nature and cannot prove cause and effect. However, an argument can be made that, within a single term and course, what faculty do is more likely to influence student engagement than student engagement is to influence what faculty do.

\section{Implications}

Evaluated in the context of the broader research, this study reinforces the broad and consistent importance of the faculty member in the student's life. The results of this study imply that how faculty express care, concern and respect for students, interact with students and are available to help can impact students' emotions and motivations, which has implications for greater achievement not only in the course in which this support and interaction occurs but also in future courses. Faculty support and faculty interactions also seem to be particularly important for under-represented students, whether females, racial/ ethnic minorities, international students or transfer students. This has important implications for faculty professional development and efforts to increase diversity and inclusion in engineering at all levels. Simply put, how faculty support and interact with students is as important as how they teach and also to varying degrees who they are interacting with - whether that be a student who is a member of a majority group or one who belongs to an under-represented group in engineering.

\section{Conclusions}

This study found that both faculty support and student-faculty interactions are significantly associated with both behavioral and emotional measures of student engagement. The nature of these associations varies with the type of engagement as well as the type of student. Students who are under-represented by race/ethnicity or gender or who are in a minority by virtue of being a transfer or international student often appear to be more responsive to faculty support and faculty interactions than majority students. These results suggest not only that those who teach engineering must be strategic in both their teaching practices and their interactions with students, but that adjusting interactions with under-represented groups may serve to support them better and enhance feelings of inclusion in engineering.

\section{References}

Anaya, G. and Cole, D.G. (2001), "Latina/o student achievement: exploring the influence of studentfaculty interactions on college grades", Journal of College Student Development, Vol. 42 No. 1, pp. 3-14.

Ancar, L.N. (2008), Social and Academic Factors of Success and Retention for Students of Color at a Predominantly White Institution in Agricultural and Engineering-Based Disciplines, $\mathrm{PhD}$ Dissertation, Iowa State University, Digital Repository, doi: 10.31274/rtd-180813-16897.

Blackburn, H. (2017), "The status of women in STEM in higher education: a review of the literature 2007-2017”, Science \& Technology Libraries, Vol. 36 No. 3, pp. 235-273, doi: 10.1080/0194262X. 2017.1371658.

Brainard, S.G. and Carlin, L. (1998), "A six-year longitudinal study of undergraduate women in engineering and science", Journal of Engineering Education, Vol. 87 No. 4, pp. 369-375.

Carnegie Foundation (2018), 2018 Classification Update, available at: http://carnegieclassifications.iu. edu/ (accessed 1 February 2020).

Cejda, B.D. (1997), "An examination of transfer shock in academic disciplines", Community College Journal of Research and Practice, Vol. 21, pp. 279-288, doi: 10.1080/1066892970210301. 
Chen, H.L., Lattuca, L.R. and Hamilton, E.R. (2008), "Conceptualizing engagement: contributions of faculty to student engagement in engineering", Journal of Engineering Education, Vol. 97 No. 3, pp. 339-353.

Cohn, M.A. and Fredrickson, B.L. (2009), "Positive emotions", Oxford Handbook Positive Psychology, Oxford University Press, Oxford, Vol. 2, pp. 13-24.

Cole, D. (2010), "The effects of student-faculty interactions on minority students' college grades: differences between aggregated and disaggregated data", Journal of the Professoriate. Vol. 3 No. 2, pp. 137-160.

Davidson, R.J., Jackson, D.C. and Kalin, N.H. (2000), "Emotion, plasticity, context, and regulation: perspectives from affective neuroscience", Psychological Bulletin, Vol. 126 No. 6, pp. 890-909.

Duchesne, S., Vitaro, F., Larose, S. and Tremblay, R.E. (2008), "Trajectories of anxiety during elementary-school years and the prediction of high school noncompletion", Journal of Youth and Adolescence, Vol. 37 No. 9, pp. 1134-1146.

Ebbin, A.J. and Blankenship, E.S. (1988), "Stress-related diagnosis and barriers to health care among foreign students: results of a survey", Journal of American College Health, Vol. 36 No. 6, pp. 311-312, doi: 10.1080/07448481.1988.9939025.

Einarson, M.K. and Clarkberg, M.E. (2010), "Race differences in the impact of students' out-of-class interactions with faculty", Journal of the Professoriate. Vol. 3 No. 2.

Eismann, L. (2016), "First-generation students and job success", available at: https://www.naceweb.org/jobmarket/special-populations/first-generation-students-and-job-success/ (accessed 1 February 2020).

Ferris, J. and Gerber, R. (1996), "Mature-age students' feelings of enjoying learning in a further education context”, European Journal of Psychology of Education, Vol. 11 No. 79, doi: 10.1007/ BF03172937.

Fredericks, J. (2013), "Behavioral engagement in learning", Educational Psychology Handbook Series. International Guide to Student Achievement, Routledge/Taylor and Francis Group, New York, pp. $42-44$.

Fredricks, J.A., Blumenfeld, P.C. and Paris, A.H. (2004), "School engagement: potential of the concept, state of the evidence", Review of Educational Research, Vol. 74, pp. 59-109.

Fredrickson, J.E. (2012), "Linking student effort to satisfaction: the importance of faculty support in creating a gain-loss frame", Academy of Educational Leadership Journal, Vol. 16, p. 111.

Gellin, A. (2003), "The effect of undergraduate student involvement on critical thinking: a meta-analysis of the literature 1991-2000", Journal of College Student Development, Vol. 44 No. 6, pp. 746-762.

George, D. and Mallery, P. (2010), SPSS for Windows Step by Step: A Simple Guide and Reference, Pearson, Boston, MA.

George, D. and Mallery, P. (2014), SPSS for Windows Step by Step: A Simple Guide and Reference, 4th ed. Allyn and Bacon, Boston, MA.

Glass, C.R., Kociolek, E., Wongtrirat, R., Lynch, R.J. and Cong, S. (2015), "Uneven experiences: the impact of student-faculty interactions on international students' sense of belonging", Journal of International Students, Vol. 5 No. 4, pp. 353-367.

Hagerty, B.M., Williams, R.A., Coyne, J.C. and Early, M.R. (1996), "Sense of belonging and indicators of social and psychological functioning", Archives of Psychiatric Nursing, Vol. 10 No. 4, pp. 235-244, doi: 10.1016/S0883-9417(96)80029-X.

Institute of International Education, (IIE) (2019), "Number of international students in the United States hits all-time high", available at: https://www.iie.org:443/en/Why-IIE/Announcements/ 2019/11/Number-of-International-Students-in-the-United-States-Hits-All-Time-High (accessed 28 January 2020).

Ishitani, T.T. and McKitrick, S.A. (2010), "After transfer: the engagement of community college students at a four-year collegiate institution”, Community College Journal of Research and Practice, Vol. 34 No. 7, pp. 576-594, doi: 10.1080/10668920701831522. 
JRIT 13,1

Johnson, D.R. (2012), "Campus racial climate perceptions and overall sense of belonging among racially diverse women in STEM majors", Journal of College Student Development, Vol. 53 No. 2, pp. 336-346, doi: 10.1353/csd.2012.0028.

Kim, Y.K. and Sax, L.J. (2011), "Are the effects of student-faculty interaction dependent on academic major? An examination using multilevel modeling", Research in Higher Education, Vol. 52, pp. 589-615.

Kim, Y.K. and Sax, L.J. (2018), "The effect of positive faculty support on mathematical self-concept for male and female students in STEM majors", Research in Higher Education, Vol. 59, pp. 1074-1104, doi: 10.1007/s11162-018-9500-8.

Komarraju, M., Musulkin, S. and Bhattacharya, G. (2010), "Role of student-faculty interactions in developing college students' academic self-concept, motivation, and achievement", Journal of College Student Development, Vol. 51, pp. 332-342, doi: 10.1353/csd.0.0137.

Kuh, G.D. and Hu, S. (2001), "The effects of student-faculty interaction in the 1990s", The Review of Higher Education, Vol. 24, pp. 309-332, doi: 10.1353/rhe.2001.0005.

LaMastro, V. (2001), "Influence of perceived institutional and faculty support on college students' attitudes and behavioral intentions”, Psychological Reports, Vol. 88 No. 2, pp. 567-580, doi: 10. 2466/pr0.2001.88.2.567.

Lamport, M.A. (1993), "Student-faculty informal interaction and the effect on college student outcomes: a review of the literature", Adolescence, Vol. 28 No. 112, pp. 971-990.

Lee, J.J. and Rice, C. (2007), "Welcome to America? International student perceptions of discrimination", Higher Education, Vol. 53, pp. 381-409, doi: 10.1007/s10734-005-4508-3.

Linnenbrink, E.A. (2007), "The role of affect in student learning: a multi-dimensional approach to considering the interaction of affect, motivation, and engagement", Emotion in Education, Elsevier, Cambridge, MA, pp. 107-124.

Linnenbrink, E.A., Ryan, A.M. and Pintrich, P.R. (1999), "The role of goals and affect in working memory functioning”, Learning and Individual Differences, Vol. 11 No. 2, pp. 213-230.

Lundberg, C.A. and Schreiner, L.A. (2004), "Quality and frequency of faculty-student interaction as predictors of learning: an analysis by student race/ethnicity", Journal of College Student Development, Vol. 45 No. 5, pp. 549-565.

Marra, R., Bogue, B., Shen, D. and Rodgers, K. (2007), "Those that leave - assessing why students leave engineering", Proceedings of the ASEE Annual Conference in Honolulu, ASEE Publications, Hawaii.

Marra, R.M., Rodgers, K.A., Shen, D. and Bogue, B. (2009), "Women engineering students and selfefficacy: a multi-year, multi-institution study of women engineering student self-efficacy", Journal of Engineering Education, Vol. 98 No. 1, pp. 27-38, doi: 10.1002/j.2168-9830.2009. tb01003.x.

Miserandino, M. (1996), "Children who do well in school: individual differences in perceived competence and autonomy in above-average children”, Journal of Educational Psychology, Vol. 88, pp. 203-214, doi: 10.1037/0022-0663.88.2.203.

National Survey of Student Engagement, (NSSE) (2019), "NSSE engagement indicators", available at: http://nsse.indiana.edu/html/engagement_indicators.cfm (accessed 4 February 2020).

National Science Foundation, (NSF) (2019), Women, Minorities, and Persons with Disabilities in Science and Engineering, available at: https://www.nsf.gov/news/news_summ.jsp?cntn_id=297944 (accessed 2 February 2020).

National Survey of Student Engagement (NSSE) (n.d.), “About NSSE”, available at: https://nsse. indiana.edu/html/about.cfm (accessed 15 February 2020).

Pekrun, R. (2006), "The control-value theory of achievement emotions: assumptions, corollaries, and implications for educational research and practice”, Educational Psychology Review, Vol. 18, pp. 315-341, doi: 10.1007/s10648-006-9029-9. 
Pekrun, R., Elliot, A.J. and Maier, M.A. (2006), "Achievement goals and discrete achievement emotions: a theoretical model and prospective test”, Journal of Educational Psychology, Vol. 98 No. 3, pp. 583-597, doi: 10.1037/0022-0663.98.3.583.

Pew Research Center (2018), Women and Men in STEM Often at Odds over Workplace Equity, available at: https://www.pewsocialtrends.org/2018/01/09/diversity-in-the-stem-workforcevaries-widely-across-jobs/ (accessed 15 February 2020).

Poyrazli, S. and Grahame, K.M. (2007), "Barriers to adjustment: needs of international students within a semi-urban campus community”, Journal of Instructional Psychology, Vol. 34 No. 1, pp. 28-45.

Puca, R.M. and Schmalt, H.D. (1999), "Task enjoyment: a mediator between achievement motives and performance", Motivation and Emotion, Vol. 23, pp. 15-29.

Rice, J.A., Levine, L.J. and Pizarro, D.A. (2007), "Just stop thinking about it: effects of emotional disengagement on children's memory for educational material”, Emotion, Vol. 7 No. 4, pp. 812-823.

Romsa, K., Bremer, K.L., Lewis, J. and Romsa, B. (2017), “The evolution of student-faculty interactions: what matters to millennial college students?”, College Student Affairs Journal, Vol. 35, pp. 85-99.

Seipp, B. (1991), "Anxiety and academic performance: a meta-analysis of findings", Anxiety Research, Vol. 4 No. 1, pp. 27-41.

Smith, R.A. and Khawaja, N.G. (2011), "A review of the acculturation experiences of international students", International Journal of Intercultural Relations, Vol. 35 No. 6, pp. 699-713.

Tinto, V. (1993), Leaving College: Rethinking the Causes and Cures of Student Attrition, University of Chicago Press, Chicago, IL.

Torregosa, M.B., Ynalvez, M.A. and Morin, K.H. (2016), "Perceptions matter: faculty caring, campus racial climate and academic performance", Journal of Advanced Nursing, Vol. 72 No. 4, pp. 864-877, doi: 10.1111/jan.12877.

Umbach, P.D. and Wawrzynski, M.R. (2005), "Faculty do matter: the role of college faculty in student learning and engagement", Research in Higher Education, Vol. 46, pp. 153-184.

Valiente, C., Swanson, J. and Eisenberg, N. (2012), "Linking students' emotions and academic achievement: when and why emotions matter", Child Development. Perspectives, Vol. 6 No. 2, pp. 129-135, doi: 10.1111/j.1750-8606.2011.00192.x.

Van Ryzin, M.J., Gravely, A.A. and Roseth, C.J. (2009), "Autonomy, belongingness, and engagement in school as contributors to adolescent psychological well-being", Journal of Youth and Adolescence, Vol. 38, pp. 1-12.

Verdin, D. and Godwin, A. (2015), "First in the family: a comparison of first-generation and non-firstgeneration engineering college students", Proceedings of the IEEE Frontiers in Education Conference in El Paso, IEEE Publishing, Texas, doi: 10.1109/FIE.2015.7344359.

Wilson, D., Jones, D.C., Bates, R.A., Smith, T.F., Plett, M. and Veilleux, N.M. (2014), "Sometimes, faculty matter: the contribution of faculty support to future engagement", Proceedings of the American Society for Engineering Education Annual Conference in Seattle, ASEE Publishing, Washington.

Wilson, D., Jones, D.C., Bates, R.A., Smith, T.F., Plett, M. and Veilleux, N.M. (2015), "Sometimes, faculty matter: the contribution of faculty support to future engagement", in ASEE American Society for Engineering Education Annual Conference in Seattle, ASEE Publishing, Washington.

\section{Corresponding author}

Denise M. Wilson can be contacted at: denisew@u.washington.edu

For instructions on how to order reprints of this article, please visit our website:

www.emeraldgrouppublishing.com/licensing/reprints.htm

Or contact us for further details: permissions@emeraldinsight.com 